\title{
Analytical Solution and Application for One-Dimensional Consolidation of Tailings Dam
}

\author{
Hai-ming Liu $\mathbb{D}$, ${ }^{1,2}$ Gan Nan, ${ }^{1}$ Wei Guo, ${ }^{1}$ Chun-he Yang, ${ }^{2}$ and Chao Zhang ${ }^{2}$ \\ ${ }^{1}$ Faculty of Civil Engineering and Mechanics, Kunming University of Science and Technology, Kunming, Yunnan 650224, China \\ ${ }^{2}$ State Key Laboratory of Geomechanics and Geotechnical Engineering, Institute of Rock and Soil Mechanics, \\ Chinese Academy of Sciences, Wuhan 430071, China \\ Correspondence should be addressed to Hai-ming Liu; haiming0871@163.com
}

Received 10 November 2017; Revised 16 January 2018; Accepted 12 February 2018; Published 19 March 2018

Academic Editor: Shuo Wang

Copyright (C) 2018 Hai-ming Liu et al. This is an open access article distributed under the Creative Commons Attribution License, which permits unrestricted use, distribution, and reproduction in any medium, provided the original work is properly cited.

\begin{abstract}
The pore water pressure of tailings dam has a very great influence on the stability of tailings dam. Based on the assumption of one-dimensional consolidation and small strain, the partial differential equation of pore water pressure is deduced. The obtained differential equation can be simplified based on the parameters which are constants. According to the characteristics of the tailings dam, the pore water pressure of the tailings dam can be divided into the slope dam segment, dry beach segment, and artificial lake segment. The pore water pressure is obtained through solving the partial differential equation by separation variable method. On this basis, the dissipation and accumulation of pore water pressure of the upstream tailings dam are analyzed. The example of typical tailings is introduced to elaborate the applicability of the analytic solution. What is more, the application of pore water pressure in tailings dam is discussed. The research results have important scientific and engineering application value for the stability of tailings dam.
\end{abstract}

\section{Introduction}

Based on the assumption that the soil is isotropic and uniform, an external surface load is instantaneously applied and is held constant; a classical one-dimensional (1D) consolidation theory was proposed by Terzaghi [1]. In order to analyze time-dependent loading, an analytical solution to the layered consolidation problem for a general set of boundary conditions and an arbitrary load history was presented by Schiffman and Stein [2]. The 1D consolidation analytical solutions considering ramp loading were presented by Olson [3]. A simple semianalytical method to solve the problem of 1D consolidation by taking into account the varied compressibility of soil under cyclic loadings was brought up by Cai et al. [4]. A rigorous solution of the conventional Terzaghi ID consolidation under haversine cyclic loading with any rest period was proposed by Müthing et al. [5], which is achieved using Fourier harmonic analysis for the periodic function representing the rate of imposition of excess pore water pressure. A semianalytical solution to $1 \mathrm{D}$ consolidation of viscoelastic unsaturated soils with a finite thickness under oedometric conditions and subjected to a sudden loading was put forward by Qin et al. [6]. A semianalytical solution to 1D consolidation equation of fractional derivative KelvinVoigt viscoelastic saturated soils subjected to different timedependent loadings was presented by Wang et al. [7]. Under the condition of the increasing weight of superincumbent material and the length of the drainage path varies, a solution for the $1 \mathrm{D}$ consolidation of a clay layer whose thickness increases with time was proposed by Gibson [8]. An exact analytical solution of the nonhomogeneous partial differential equation governing the conventional 1D consolidation under haversine repeated loading was derived and discussed by Razouki et al. $[9,10]$.

In order to analyze different boundary conditions, single drainage solutions for several specific variations of the permeability and shear modulus were given by Mahmoud and Deresiewicz [11]. Several analytical solutions for the consolidation analysis of a soil layer with fairly general laws of variation of permeability and compressibility for both a single-drained condition and a double-drained condition were proposed by Zhu and Yin [12]. Tang et al. [13] propose 
a closed-form solution for consolidation of three-layered soil with a vertical drain system and a method to solve a convergence solution by enlarging the precision for the entire thickness of the foundation and adding controlling precision for the overall average degree of consolidation of each soil layer. The solution of Terzaghi $1 \mathrm{D}$ consolidation equation with general boundary conditions is proposed by Mei and Chen [14], whose solution is validated by comparing it to the classical solution. Hawlader et al. [15] develop a new constitutive model for the compressibility behavior of soft clay sediments at low effective stress level and the model is used to solve finite strain 1D consolidation with pertinent initial and boundary conditions. A solution to the consolidation equation with boundary conditions that are cyclic with time is given by Rahalt and Vuez [16]. A nonlinear theory of consolidation has been developed for an ideal normally consolidated soil by Davis and Raymond [17]. A simple calculation procedure to analyze the one-dimensional response of saturated soil layers to pore pressure variations at the boundary described by a general time-dependent function is developed by Conte and Troncone [18].

The tailings dam is an important geotechnical structure in mining engineering. For a long time, the theory of reservoir dam is applied to tailings dam without any modification. However, there are many differences between tailings dam and reservoir dam, which lead to inaccurate calculation results of the pore water pressure. According to the classical Terzaghi consolidation theory, the analytical solution of the pore water pressure is discussed in this paper.

\section{The General Equation of $1 D$ Consolidation}

According to Darcy's law, the flow drag resistance of the $z$ direction is as follows:

$$
F_{z}=-i_{z} \gamma_{w}=-n \frac{\gamma_{w}}{k} v_{z}
$$

The negative sign on the right side of (1) indicates that the drag resistance is opposite to the direction of flow velocity.

According to the mechanical equilibrium conditions, the flow drag resistance of the $z$-direction can also be expressed as follows:

$$
F_{z}=\frac{\partial p_{w}}{\partial z}+\gamma_{w}
$$

Equations (1) and (2) can be combined as follows:

$$
\frac{\partial p_{w}}{\partial z}+\gamma_{w}+n \frac{\gamma_{w}}{k} v_{z}=0
$$

It is assumed that the water in porosity is incompressible under the consolidation process. Thus, $\gamma_{w}$ is a constant. During the process of soil consolidation, because the porosity of soil particles is continuously compressed, the permeability coefficient of soil is decreased continuously and the permeability coefficient $k$ of soil is changed with depth, that is, $k=f(z)$. Taking the derivative of (3), one can have

$$
\frac{\partial^{2} p_{w}}{\partial z^{2}}+n \gamma_{w} \frac{\partial}{\partial z}\left(\frac{v_{z}}{k}\right)=0
$$

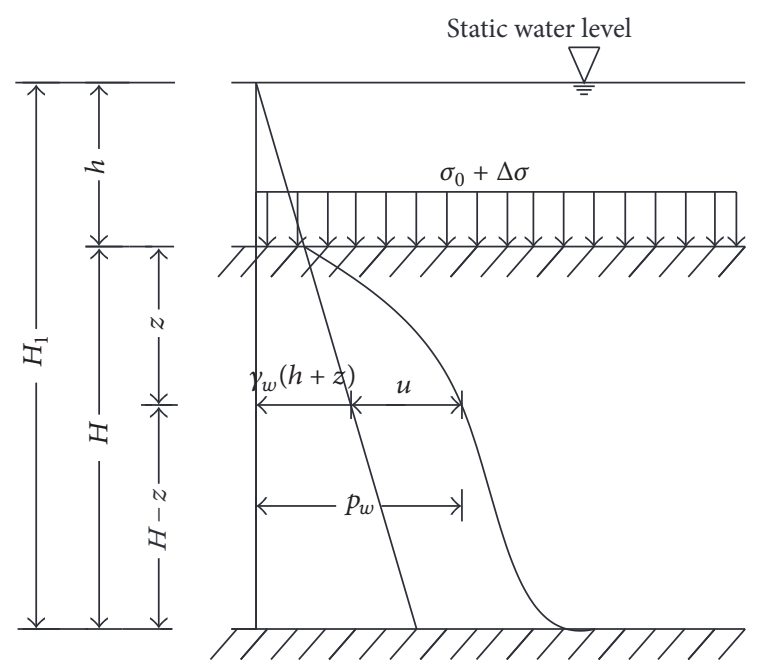

FIgURE 1: Schematic diagram of stress in soil.

According to fractional derivative rule, (4) can be expanded as follows:

$$
\frac{\partial^{2} p_{w}}{\partial z^{2}}+n \gamma_{w} \frac{1}{k} \frac{\partial v_{z}}{\partial z}-n \gamma_{w} v_{z} \frac{1}{k^{2}} \frac{d k}{d z}=0
$$

Assume that the horizontal direction consolidation of the soil can be neglected; that is, the consolidation is under confined compression condition. According to the $1 \mathrm{D}$ consolidation condition, (6) can be deduced

$$
n \frac{\partial v_{z}}{\partial z}=\frac{\partial \varepsilon_{z}}{\partial t}
$$

Under the condition of $1 \mathrm{D}$ consolidation, the axial strain $\varepsilon_{v}$ is equal to the volume strain $\varepsilon_{v}$ of the soil. According to Pane and Schiffman [19] research, (4) and (5) can be rewritten as follows:

$$
\begin{array}{r}
\frac{\partial^{2} p_{w}}{\partial z^{2}}+\frac{\gamma_{w}}{k} \frac{\partial \varepsilon_{z}}{\partial t}=0 \\
\frac{\partial^{2} p_{w}}{\partial z^{2}}+\frac{\gamma_{w}}{k} \frac{\partial \varepsilon_{z}}{\partial t}-n \gamma_{w} v_{z} \frac{1}{k^{2}} \frac{d k}{d z}=0
\end{array}
$$

In the consolidation problem, it is of great significance to study the change of pore water pressure with time and position under external load. Therefore, (8) can be expanded according to pore water pressure.

Assuming that the soil profile is shown as Figure 1, the pore water pressure of a point located $z$ under load $\sigma_{0}$ and $\Delta \sigma_{0}$ is $u$. According to the Terzaghi effective stress principle, the effective stress $\sigma^{\prime}$ could be given as follows under consolidation:

$$
\sigma^{\prime}=\sigma-p_{w}=\sigma-\left[\gamma_{w}(h+z)+u\right] .
$$

According to Figure 1, the total stress $\sigma$ of a point located $z$ is as follows:

$$
\sigma=\left(\sigma_{0}+\Delta \sigma\right)+\gamma_{s} z+\gamma_{w} h
$$




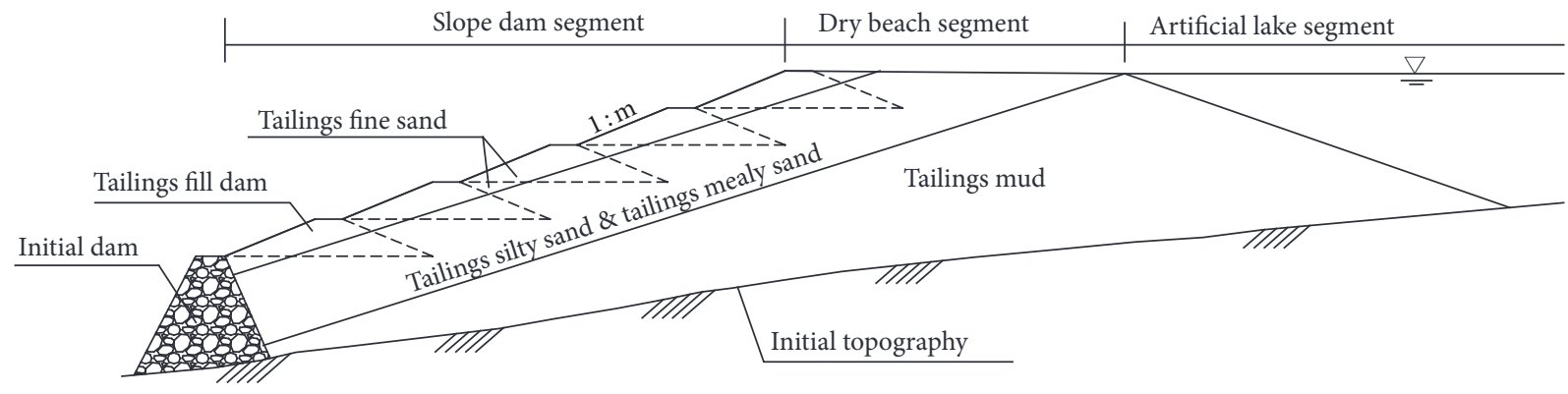

Figure 2: Schematic diagram of the upstream tailings dam.

Substituting (10) into (9) yields

$$
\sigma^{\prime}=\left(\sigma_{0}+\Delta \sigma\right)+\gamma^{\prime} z-u
$$

Take the derivative of (11) with respect to $t$ and consider the relationship $\partial z / \partial t$ equals $\partial H / \partial t$

$$
\frac{\partial \sigma^{\prime}}{\partial t}=\frac{\partial}{\partial t}(\Delta \sigma)+\gamma^{\prime} \frac{\partial H}{\partial t}-\frac{\partial u}{\partial t}
$$

According to the compression curve of $1 \mathrm{D}$ consolidation test, the volume compressibility factor $m_{v}$ can be defined as follows:

$$
\begin{aligned}
m_{v} & =\frac{1}{1+e} \frac{\partial e}{\partial \sigma^{\prime}} \\
\frac{\partial \varepsilon_{z}}{\partial t} & =\frac{1}{1+e} \frac{\partial e}{\partial t}
\end{aligned}
$$

Substituting (13) into (14) gives

$$
\frac{\partial \varepsilon_{z}}{\partial t}=m_{v} \frac{\partial \sigma^{\prime}}{\partial t}
$$

Substituting (15) into (8), it is noted that the last term of (8) has the following relation:

$$
n \gamma_{w} v_{z} \frac{1}{k^{2}} \frac{d k}{d z}=-F_{z} \frac{1}{k} \frac{d k}{d z}=-\left(\frac{\partial p_{w}}{\partial z}+\gamma_{w}\right) \frac{1}{k} \frac{d k}{d z} .
$$

Equation (8) can be derived as

$$
\frac{\partial^{2} p_{w}}{\partial z^{2}}+\frac{m_{v} \gamma_{w}}{k} \frac{\partial \sigma^{\prime}}{\partial t}+\left(\frac{\partial p_{w}}{\partial z}+\gamma_{w}\right) \frac{1}{k} \frac{d k}{d z}=0 .
$$

Substituting (15) into (17), (17) can be expressed as pore water pressure. Equation (18) can be obtained

$$
\frac{\partial^{2} u}{\partial z^{2}}+\frac{m_{v} \gamma_{w}}{k}\left[\frac{\partial \Delta \sigma}{\partial t}+\gamma^{\prime} \frac{\partial H}{\partial t}-\frac{\partial u}{\partial t}\right]+\frac{1}{k} \frac{d k}{d z} \frac{\partial u}{\partial z}=0 .
$$

Equation (18) is a general equation which reflects the $1 \mathrm{D}$ consolidation process. It takes into account the situation where the applied load changes with time, the soil thickness changes with time, the soil permeability changes with depth, and so on.

\section{Accumulation and Dissipation of Pore Water Pressure in Tailings Dam}

Tailings are mine wastes produced in the mining engineering, which are sent to tailings reservoir by pipe or flume. The tailings dam is an important part in mining engineering, which is consisted by the initial dam and fill dam. The initial dam is made by permeable rockfill generally, and the fill dam is formed by tailings. In general, the construction of a tailing dam takes many decades or even a century. According to construction method, the tailings dam can be divided into upstream tailings dam, downstream tailings dam, midline method tailings dam, and so on. The number of tailings ponds in China has reached more than 12,000 by statistics. Because the downstream of the tailings dam is residents living area or mining production area generally the social and people's property damage a huge impact if the tailings dam is failed.

Because the upstream tailings dam has advantages of simple operation, low construction costs, the less need for coarse particles, and so on, according to statistics, 95\% of the tailings dams are adopting the construction of the upstream tailings dam in China. On the other hand, the construction process of the upstream tailings dam cannot precisely control the shape of the tailings dam. The deposition structure of the tailings dam is very complex. The upstream tailings have shortcoming of long infiltration distant and poor stability. In view of the tailings slurry discharge and tailings particle deposition following the sediment mechanics, the section profile of the tailings dam has obvious regularity. The coarser the particle size is, the shorter the average distance migrates and vice versa. Generally, the deposition order of the tailings dam along the dry beach face is tailings fine sand, tailings silt, tailings sand, and tailings mud.

If particle size distribution of the tailings and the length of the dry beach face are kept constant, the interface of the tailings material should be substantially parallel to the surface of the dam slope, which is shown in Figure 2. For most of the tailings dams, because the tailings water contains more heavy metals, the initial topography and the side of tailings dam are treated as an impermeable boundary. On the other hand, the tailings dam extends very long in the direction of the reservoir area. Therefore, the consolidation of the tailings dam is a $1 \mathrm{D}$ problem.

As can be seen from Figure 2, the closer to inside the reservoir area is, the thicker the tailings mud is and the worse 
the average consolidation is. In other words, the closer to inside the reservoir area is, the greater pore water pressure of the tailings dam is and the lower shear strength of the tailings material is. Generally speaking, the construction of a tailings dam needs several decades to reach the design elevation. With the continuous production of mining, the height of the tailings dam is increasing. During this process, the accumulation and dissipation of the excess pore water pressure of the tailings material experience several different stages of development.

3.1. Tailings Thickness Increases with Time. In this stage, the thickness of the tailings increases with time. The tailings material produces great compressive deformation under selfweight effect. The pore water pressure produced by the selfweight pressure at the early stage is partially dissipated. Nevertheless, the pore water pressure caused by self-weight pressure is increased with the tailings thickness at the later stage, which leads to the increase of the pore water pressure with time. Therefore, the net pore water pressure is accumulated during this process.

3.2. Load on the Tailings Layer Increases with Time. The selfdeposition of the tailings mud continues to extend to interior of the tailings reservoir area in this stage. The self-deposition of the tailings layer has ended where the end of the tailings reservoir is near. It overlapped with particles coarse tailings and tailings mud. The tailings mud has to bear a growing load with time. The tailings mud continues to consolidate under the combined action of self-weight and additional load. At this stage, the pore pressure produced by the selfweight pressure dissipates a little part, and the more pore water pressure produced by additional load accumulates. The net pore water pressure tends to accumulate in this process.

3.3. The Additional Load of the Tailings Material Remains Constant. For a specific part of the tailings dam, the upper boundary of the tailings dam has reached the designed elevation at a certain moment. Therefore, the additional load will remain unchanged from this moment. During this stage, the tailings mud will continue to consolidate under the combined action of self-weight and constant additional load. Thus, the pore water pressure will dissipate within the tailings dam. Obviously, the different parts of tailings mud have different consolidation stages. There is no additional load at the thickest tailings mud in the tailings reservoir until it is closed. Therefore, the tailings mud is always in the first stage and will never enter the second and third stages. From the above qualitative analysis, the pore water pressure, which is located at the slope dam segment, reaches the maximum value when the additional load just stops growing. The pore water pressure, which is located at dry beach segment and artificial lake segment, achieves the maximum value when the tailings dam reaches the maximum height. The numerical values of the pore water pressure at different locations and moments can be obtained by solving the partial differential equations of consolidation problems.

\section{Analytical Solutions of the Pore Water Pressure}

It is necessary to accurately calculate the accumulation and dissipation of the pore water pressure in tailings dam, of which a solution of $1 \mathrm{D}$ consolidation problem can be simplified. During the consolidation process, the soil parameters of tailings material (such as the change of bulk density, permeability coefficient, and consolidation coefficient) are changed with the consolidation process. The change law can be determined through many experiments. Under normal circumstances, it is difficult to obtain the analytical solution when the change law of soil parameters is considered. Therefore, the exact solution of the problem can only be depended on numerical calculation method.

As the horizontal length of the tailings reservoir is usually far greater than the vertical thickness (i.e., the horizontal length is 10 times more than the vertical thickness), the drainage consolidation effect of the horizontal direction can be ignored. Therefore, the vertical direction of drainage is needed to consider. Then, it is only a $1 \mathrm{D}$ consolidation problem. Based on the assumption of small-strain and constant of soil parameters, such as $m_{v}, k, \partial \Delta \sigma / \partial t, \gamma^{\prime}$, and $\partial H / \partial t$ are constant, (18) is degenerated into a constant coefficient nonhomogeneous parabolic partial differential equation

$$
\frac{\partial^{2} u}{\partial z^{2}}+\frac{1}{c_{\nu}}\left(\alpha+\gamma^{\prime} Q-\frac{\partial u}{\partial t}\right)=0,
$$

where

$$
\begin{gathered}
\alpha=\frac{\partial \Delta \sigma}{\partial t}, \\
Q=\frac{\partial H}{\partial t} \\
c_{v}=\frac{k}{m_{\nu} \gamma_{w}} .
\end{gathered}
$$

The above three different stages are specifically discussed as follows.

4.1. The Thickness Mud of Tailings Mud Increases with Time. The overburden load of the tailings mud at this stage is zero, that is, $\alpha=0$. The consolidation equation yields

$$
\frac{\partial^{2} u}{\partial z^{2}}+\frac{1}{c_{v}}\left(\gamma^{\prime} Q-\frac{\partial u}{\partial t}\right)=0 .
$$

If the bottom of the tailings mud is impermeable, the coordinates origin is taken as the impermeable bottom. The boundary conditions of the problem can be given as follows:

$$
\begin{aligned}
z & =0, \\
\frac{\partial u}{\partial z} & =0, \\
z & =H, \\
u & =0 .
\end{aligned}
$$


The initial condition of the problem is given by

$$
\begin{aligned}
& t=0, \\
& u=0 .
\end{aligned}
$$

According to Gibson's [20] study, (25) is chosen as the solution of (21)

$$
\begin{aligned}
u= & \gamma^{\prime} h \\
& -t^{-1 / 2} \int_{0}^{\infty} g(\xi)\left(e^{-(x-\xi)^{2} / 4 c_{\nu} t}+e^{-(x+\xi)^{2} / 4 c_{y} t}\right) d \xi .
\end{aligned}
$$

It can be verified that (25) satisfies the boundary condition (22). The choice of function $g(\xi)$ needs to satisfy (23). Substituting (25) into (23) gives

$$
\frac{1}{2} \gamma^{\prime} h t^{1 / 2} e^{h^{2} / 4 c_{\nu} t}=\int_{0}^{\infty} g(\xi) e^{-(x+\xi)^{2} / 4 c_{\nu} t} \cosh \frac{h \xi}{2 c_{v} t} d \xi .
$$

For any function $h(t)$, the partial differential equation (26) has no numerical solution. With regard to $h(t)=m t$, the following parameters can be introduced to transform the equation

$$
\begin{aligned}
\xi^{2} & =\tau, \\
p & =\frac{1}{4} c_{v} t, \\
F(\tau) & =g(\tau) \tau^{-1 / 2} \cosh \frac{k \tau^{1 / 2}}{2 c_{v}} .
\end{aligned}
$$

Equation (26) can be transformed into

$$
\frac{1}{8} m \gamma^{\prime} c_{v}^{-3 / 2} p^{-3 / 2} e^{m^{2} / 16 c_{v}{ }^{2} p}=\int_{0}^{\infty} F(\tau) e^{-p \tau} d \tau .
$$

Equation (28) can be obtained through the Laplace change:

$$
F(\tau)=\frac{\gamma^{\prime}}{2 \pi^{1 / 2} c_{v}{ }^{1 / 2}} \sinh \frac{m \tau^{1 / 2}}{c_{v}}
$$

Thence

$$
g(\xi)=\frac{\gamma^{\prime} \xi}{2 \pi^{1 / 2} c_{v}{ }^{1 / 2}} \tanh \frac{m \xi}{c_{v}} .
$$

Combining the solutions of (25) and (30), the solution of (21) is obtained

$$
\begin{gathered}
u=\gamma^{\prime} Q t-\gamma^{\prime}\left(\pi c_{\nu} t\right)^{-1 / 2} \exp \left(\frac{-z^{2}}{4 c_{\nu} t}\right) \int_{0}^{\infty} \xi \tanh \frac{Q \xi}{2 c_{\nu}} \\
\cdot \cosh \frac{z \xi}{2 c_{\nu} t} \exp \left(\frac{-\xi^{2}}{2 c_{\nu} t}\right) d \xi .
\end{gathered}
$$
(24).

It can be verified that (31) satisfies the initial condition of
4.2. The Additional Load of Tailings Mud Increases with Time. During this stage, the thickness of tailings mud not only does not increase with time but also gradually decreases with the increase of effective stress. For the sake of simplicity, assuming that the thickness of tailings mud $H$ is constant, the basic consolidation differential (19) can be simplified as

$$
c_{\nu} \frac{\partial^{2} u}{\partial z^{2}}=\frac{\partial u}{\partial t}-\frac{\partial \Delta \sigma}{\partial t} .
$$

The initial condition of the problem is given by

$$
\begin{aligned}
& t=t_{1}, \\
& u=u_{0}(z) .
\end{aligned}
$$

The boundary conditions of the problem can be given as

$$
\begin{aligned}
z & =0, \\
u & =0 \\
z & =H, \\
\frac{\partial u}{\partial z} & =0 .
\end{aligned}
$$

The following three questions are called problem $A$, problem $B$, and problem $C$, respectively:

A:

$$
\frac{\partial u}{\partial t}=c_{v} \frac{\partial^{2} u}{\partial z^{2}}
$$

Initial conditions: $t=t_{1}$,

$$
\begin{aligned}
u & =u_{0}(z) \\
\text { Boundary conditions: } & z=0, \\
u & =0 \\
z & =H, \\
\frac{\partial u}{\partial z} & =0 .
\end{aligned}
$$

$B:$

$$
\frac{\partial u}{\partial t}=c_{v} \frac{\partial^{2} u}{\partial z^{2}}+\frac{\partial \Delta \sigma}{\partial t}
$$

Initial conditions: $t=t_{1}$,

$$
u=0
$$

Boundary conditions: $\quad z=0$,

$u=0$

$z=H$,

$\frac{\partial u}{\partial z}=0$. 
C:

$$
\begin{array}{cl}
\text { Initial conditions: } & t=t_{1}, \\
& u_{0}(z) \\
\text { Boundary conditions: } & z=0, \\
& u=0 \\
& z=H, \\
& \frac{\partial u}{\partial z}=0 .
\end{array}
$$$$
\frac{\partial u}{\partial t}=c_{\nu} \frac{\partial^{2} u}{\partial z^{2}}+\frac{\partial \Delta \sigma}{\partial t}
$$

If the solution of problem $A$, problem $B$, and problem $C$ is $u_{A}, u_{B}$, and $u_{C}$ respectively, it can be directly proved through substitution method:

$$
u_{C}=u_{A}+u_{B} .
$$

The solution of $u_{A}$ belongs to the Terzaghi classical 1D consolidation problem. The analytical solution can be obtained.

$$
u_{A}=\sum_{j=1}^{\infty} A_{n} \sin \frac{j \pi z}{2 H} \exp \left[\frac{-j^{2} \pi^{2} c_{v}\left(t-t_{1}\right)}{4 H^{2}}\right],
$$

where

$$
A_{n}=\frac{1}{H} \int_{0}^{2 H} u_{0}(z) \sin \frac{j \pi z}{2 H} d z
$$

$u_{0}(z)$ is the solution of (31). Substituting (31) into (40) by Matlab software, $A_{n}$ can be obtained. Substituting it into (39), the numerical solution $u_{A}$ can be given.

For solution to the problem $u_{B}$, Schiffman [21] acquires the following series solutions:

$$
\begin{aligned}
u_{B}= & \frac{16 \alpha H^{2}}{\pi^{3} c_{v}} \sum_{1,3,5}^{\infty} \frac{1}{j^{3}} \sin \frac{j \pi z}{2 H} \\
& \cdot\left\{1-\exp \left[\frac{-j^{2} \pi^{2} c_{v}\left(t-t_{1}\right)}{4 H^{2}}\right]\right\} .
\end{aligned}
$$

When the tailings mud is below the groundwater level, the total stress $\sigma(z)$ of the tailings mud at the depth $z$ can be expressed as follows:

$$
\sigma(z)=\gamma^{\prime} z+\frac{\partial \Delta \sigma}{\partial t}\left(t-t_{1}\right) .
$$

The ratio of pore water pressure to total stress can be easily determined as follows:

$$
U_{z}=\frac{u_{A}+u_{B}}{\sigma(z)} .
$$

4.3. The Additional Load on the Tailings Mud Remains Constant. In this stage, the basic differential equation and the definite condition are problem $D$ :

D:

$$
\begin{aligned}
\frac{\partial u}{\partial t} & =c_{v} \frac{\partial^{2} u}{\partial z^{2}} \\
t & =t_{2}, \\
u & =\left.\left(u_{A}+u_{B}\right)\right|_{t=t_{2}} \\
z & =0, \\
u & =0 \\
z & =H, \\
\frac{\partial u}{\partial z} & =0 .
\end{aligned}
$$

The following questions can be called problem $E$ :

E:

$$
\begin{aligned}
\frac{\partial u}{\partial t} & =c_{v} \frac{\partial^{2} u}{\partial z^{2}} \\
t & =t_{2}, \\
u & =\left.u_{B}\right|_{t=t_{2}}=u_{1}(z) \\
z & =0, \\
u & =0 \\
z & =H, \\
\frac{\partial u}{\partial z} & =0 .
\end{aligned}
$$

If the solution of problem $A$ is $u_{A}$ and the solution of problem $E$ is $u_{E}$, the solution of problem $D$ can be easily demonstrated is $u_{D}$ as follows:

$$
u_{D}=u_{A}+u_{E} .
$$

The definite condition of problem $E$ and problem $A$ is exactly the same in form, except that the function $u_{1}(z)$ is different from the function $u_{0}(z)$.

Suppose that

$$
u_{E}=\sum_{j=1}^{\infty} B_{n} \sin \frac{j \pi z}{2 H} \exp \left[\frac{-j^{2} \pi^{2} c_{v}\left(t-t_{2}\right)}{4 H^{2}}\right] .
$$

Then

$$
B_{n}=\frac{1}{H} \int_{0}^{2 H} u_{1}(z) \sin \frac{j \pi z}{2 H} d z,
$$

where

$$
\begin{aligned}
& u_{1}(z)=\frac{16 \alpha H^{2}}{\pi^{3} c_{v}} \\
& \cdot \sum_{1,2,3}^{\infty} \frac{1}{j^{3}} \sin \frac{j \pi z}{2 H}\left\{1-\exp \left[\frac{-j^{2} \pi^{2} c_{v}\left(t_{2}-t_{1}\right)}{4 H^{2}}\right]\right\} .
\end{aligned}
$$




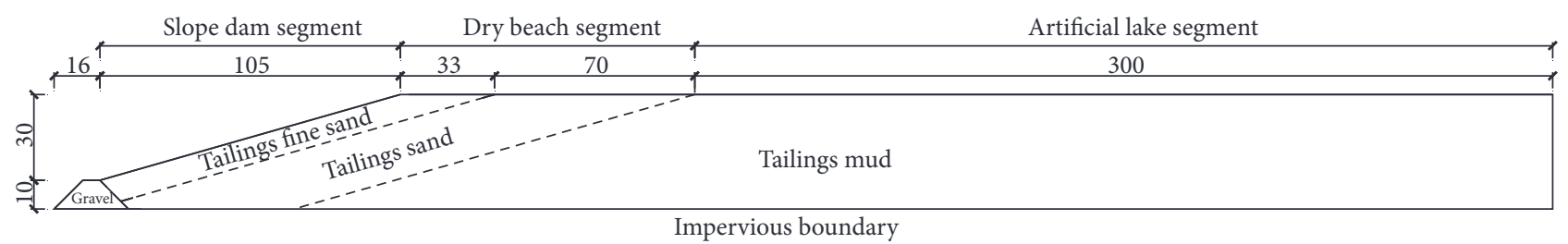

FIGURE 3: Simplified section for calculation of pore water pressure in a tailings dam.

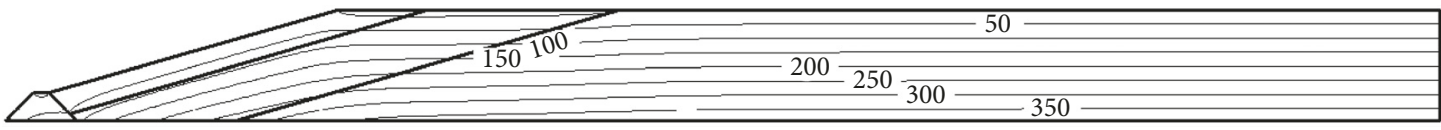

FIGURE 4: Distribution of pore water pressure at the moment when the dam rises to its maximum height.

According to the orthogonal rule of the solution, the following relationship can be obtained:

$$
\frac{1}{H} \int_{0}^{2 H} \sin \frac{m \pi z}{2 H} \sin \frac{j \pi z}{2 H} d z= \begin{cases}0, & m \neq j \\ 1, & m=j .\end{cases}
$$

Equation (48) can be simplified through (50)

$$
\begin{aligned}
& B_{n} \\
& = \begin{cases}\frac{16 \alpha H^{2}}{\pi^{3} c_{v}} \frac{1}{j^{3}}\left\{1-\exp \left[\frac{-j^{2} \pi^{2} c_{v}\left(t_{2}-t_{1}\right)}{4 H^{2}}\right]\right\} & j=1,3,5 \\
0 & j=2,4,6 .\end{cases}
\end{aligned}
$$

Substituting (51) into (47) yields

$$
\begin{aligned}
& u_{E}=\frac{16 \alpha H^{2}}{\pi^{3} c_{v}} \sum_{1,3,5}^{\infty} \frac{1}{j^{3}}\left\{1-\exp \left[\frac{-j^{2} \pi^{2} c_{v}\left(t_{2}-t_{1}\right)}{4 H^{2}}\right]\right\} \\
& \cdot \sin \frac{j \pi z}{2 H} \exp \left[\frac{-j^{2} \pi^{2} c_{v}\left(t-t_{2}\right)}{4 H^{2}}\right] .
\end{aligned}
$$

For the third stage, the analytical solution of pore water pressure is obtained.

Similar to (42), the ratio of pore water pressure to total stress at a certain depth of tailings mud at this stage is as follows:

$$
U_{z}=\frac{u_{A}+u_{E}}{\sigma(z)}
$$

During this stage, $\sigma(z)$ does not change with time, and it can take the following value:

$$
\sigma(z)=\gamma^{\prime} z+\alpha\left(t_{2}-t_{1}\right)
$$

\section{Example}

The simplified calculation section of the representative section of a tailings dam is shown in Figure 3. The length of the tailings dam is $368 \mathrm{~m}$. Therefore, the problem can be simplified as 1D consolidation. The slime layer below the level is assumed for impervious boundary. The rising speed of the dam height is $1.75 \mathrm{~m} / \mathrm{y}$. The saturation density of gravel is $22.0 \mathrm{kN} / \mathrm{m}^{3}$, the saturation density of the tailings fine sand is $19.6 \mathrm{kN} / \mathrm{m}^{3}$, the saturation density of the tailings sand is $19.1 \mathrm{kN} / \mathrm{m}^{3}$, and the saturation density of the tailings mud is $18.8 \mathrm{kN} / \mathrm{m}^{3}$. The permeability coefficient of gravel is $3 \times$ $10^{-3} \mathrm{~m} / \mathrm{s}$, the permeability coefficient of the tailings fine sand is $5 \times 10^{-6} \mathrm{~m} / \mathrm{s}$, the permeability coefficient of the tailings sand is $2 \times 10^{-6} \mathrm{~m} / \mathrm{s}$, and the permeability coefficient of the tailings mud is $1.5 \times 10^{-8} \mathrm{~m} / \mathrm{s}$. The consolidation coefficient of gravel is $3.8 \times 10^{-1} \mathrm{~cm}^{2} / \mathrm{s}$, the consolidation coefficient of the tailings fine sand is $5.4 \times 10^{-3} \mathrm{~cm}^{2} / \mathrm{s}$, the consolidation coefficient of the tailings sand is $2.8 \times 10^{-3} \mathrm{~cm}^{2} / \mathrm{s}$, and the consolidation coefficient of the tailings mud is $1.2 \times 10^{-5} \mathrm{~cm}^{2} / \mathrm{s}$. Please determine the distribution of pore water pressure when the tailings dam reaches maximum height.

The above problem can be solved through (31), (46), and (52). The calculation can be accomplished through the MATLAB software. Firstly, a coordinate system can be set up. Then, the corresponding coordinates are taken out of the interval $1 \mathrm{~m}$. The region is determined according to the coordinates. Then, the pore water pressure can be calculated through the corresponding equation. Finally, the contour map can be drawn through a set of array. The results of the calculation are shown in Figure 4.

\section{Discussion}

Due to the similarity between the tailings dam and the reservoir dam in the geotechnical structure, many scholars directly introduce the calculation methods of the reservoir dam, whose theory is relatively mature, into the tailings dam. Considering the difference on construction cycle, construction materials between the tailings dam and reservoir dam, it makes the calculation results inconsistent with the actual.

Based on the Terzaghi consolidation theory of $1 \mathrm{D}$, the tailings dam is divided into the slope dam segment, the dry beach segment, and the artificial lake segment. The solutions of the pore water pressure are derived, respectively. The analysis shows that the additional load of the slope dam segment is unchanged, which can be calculated using (46). The analysis indicates that tailings thickness of the artificial 
lake segment increases with time during construction period, which can be calculated by (31). The situation of the dry beach section is slightly complicated. The additional load of the dry beach section which is under the slope dam segment is basically the same, which can be calculated by (52). The additional load on the other sections of the dry beach segment increases with time, which can be calculated using (31).

The theoretical derivation is based on $1 \mathrm{D}$ consolidation theory. It is only considering consolidation in the vertical direction. Since the horizontal scale of most tailings dams is much larger than the vertical direction, it has little influence to ignore the drainage of horizontal. From the point of engineering view, it is conservative to the stability of the tailings dam. Considering drainage of the horizontal, the pore water pressure will be lessened and the safety factor of the tailings dam will be greater.

It is assumed that the deformation of the tailings is small deformation during the consolidation process. If the actual tailings are loose relatively, the deformation of the tailings is large deformation. He et al. [22] studied the pore water pressure of saturated soils using the updated Lagrangian formulation of large strain method (ULM), total Lagrangian formulation of large strain method (TLM), and small strain method (SSM). The results point out that the pore water pressure of the above three methods is exactly the same when the strain is less than $2.4 \%$. When the strain is greater than $2.4 \%$, the pore water pressure of the ULM and SSM still keeps the same, and the pore water pressure of the TLM is obviously less than the ULM and SSM. When the strain reaches $7.5 \%$, the pore water pressure of the ULM and SMM began to bifurcate. When the deformation of the tailings dam is examined for a relatively short time, the consolidation of prophase tailings dam has been completed under previous load. The consolidation deformation of the whole tailings dam is relatively small, and its deformation conforms to the small deformation assumption. On the other hand, it is difficult to calculate and solve partial differential equations using large deformation theory. The differences between large deformation and small deformation need to be further studied.

It is supposed that the mechanical parameters such as permeability coefficient and consolidation coefficient are constant during the consolidation process. Previous studies [23] have shown that the permeability coefficient of rock and soil decreases with the increase of deformation during the consolidation process. It is believed that the value of $C_{c} / C_{k}$ decides whether it is necessary to take under consideration the effect of nonlinear property by Zhuang et al. [24]. The results show that pore water pressure calculated depends on the ratio of loading intensity to the initial effective vertical stress subjected to time-dependent loading by Conte and Troncone [25]. How the permeability coefficient of tailings material changes during the consolidation process is less studied by relevant scholars. How the permeability coefficient of tailings material changes during the consolidation process is less studied by relevant scholars. From the aspect of engineering view, the larger the pore water pressure of actual is, the smaller the safety factor of tailings dam is. Therefore, it is dangerous for the tailings dam. The law of permeability coefficient of tailing material during consolidation process needs to be further studied.

\section{Conclusion}

Tailings dam is a very important geotechnical structure of mine engineering. The calculation of pore water pressure has a great impact on the safety factor of tailings dam slope. How to accurately estimate pore water pressure is very difficult. Based on the assumption of 1D consolidation and small strain of tailings material, a general equation of the pore water pressure is proposed. According to dissipation and accumulation characteristics of the pore water pressure in the tailings dam, the tailings dam can be divided into the slope dam segment, the dry beach segment, and the artificial lake segment. The analytic solutions of the corresponding segment are obtained through solving the partial differential equation, which has great significance to the stability of the tailings dam.

\section{Notations}

$\tau$ : $\quad$ Shear strength of the tailings material

$\sigma(z)$ : Maximum increases in vertical total stress as a function of depth $z$

$\xi$ : $\quad$ A parameter introduced to transform an equation

$\alpha$ : The rate of the additional load on the tailings mud, $\alpha=\partial \Delta \sigma / \partial t$

$x: \quad$ Coordinate of $x$ direction

$p$ : A parameter introduced to transform an equation

$n$ : Porosity of the tailings material

$m, j$ : Counters, $1,2,3, \ldots$

$g(\tau)$ : A function of variable $\tau$

$g(\xi)$ : A function introduced into solving partial differential equation

Q: $\quad$ The rate of the thickness of the tailings mud, $Q=\partial H / \partial t$

$F(\tau)$ : A function introduced to transform an equation

$\sigma: \quad$ Stress of the tailings material

$z$ : $\quad$ Coordinate of $z$ direction

$u$ : The pore water pressure

$k$ : $\quad$ Coefficient of coefficient

$h$ : The height of static water level

$H$ : Thickness of tailings mud

$e$ : Porosity ratio

$\Delta \sigma: \quad$ Increment of stress

$u_{1}(z)$ : Termination pore water pressure as a function of depth $z$

$u_{0}(z)$ : Initial pore water pressure as a function of depth $z$

$t_{2}$ : Termination time

$t_{1}$ : Initial time

$c_{\gamma}$ : Coefficient of consolidation

$U_{z}:$ Saturation

$B_{n}$ : Coefficients to be determined 
$A_{n}$ : Coefficients to be determined

$\sigma_{0}$ : Initial total stress

$\sigma^{\prime}$ : Effective vertical stress

$\varepsilon_{z}:$ Strain in the $z$ direction

$\gamma_{w}$ : Bulk density of water

$\gamma_{s}$ : Saturated bulk density of tailings dam

$\gamma^{\prime}$ : Buoyancy unit weight of tailings material

$v_{z}$ : The actual velocity along the flow direction in the tailings dam

$p_{w}$ : Water pressure

$m_{v}$ : Coefficient of volume compressibility

$i_{z}$ : Hydraulic gradient in the $z$ direction

$H_{1}$ : The total height of tailings mud plus static water level

$F_{z}$ : The drag resistance force on the pore wall of a unit volume in the $z$ direction.

\section{Conflicts of Interest}

The authors declare that they have no conflicts of interest.

\section{Acknowledgments}

This paper is supported by the Open Research Fund of State Key Laboratory of Geomechanics and Geotechnical Engineering, Institute of Rock and Soil Mechanics, Chinese Academy of Sciences, (Grant no. Z013009), the National Key Research and Development Program of China (Project no. 2017YFC0804601), the National Natural Science Foundation of China (Grant nos. 51764020; 51741410; 51234004), and the Natural Science Foundation of Yunnan Province (Grant no. 2015FB130). The authors would like to thank them for providing the financial support for conducting this research.

\section{References}

[1] K. Terzaghi, Theoretical Soil Mechanics, John Wiley \& Sons, New York, NY, USA, 1943.

[2] R. L. Schiffman and J. R. Stein, "One-dimensional consolidation of layered systems," Journal of the Soil Mechanics and Foundations Division, vol. 96, no. 4, pp. 1499-1504, 1970.

[3] R. E. Olson, "Consolidation under time-dependent loading," Journal of the Geotechnical Engineering Division, vol. 103, no. 1, pp. 55-60, 1977.

[4] Y.-Q. Cai, X.-Y. Geng, and C.-J. Xu, "Solution of one-dimensional finite-strain consolidation of soil with variable compressibility under cyclic loadings," Computers \& Geosciences, vol. 34, no. 1, pp. 31-40, 2007.

[5] N. Müthing, S. S. Razouki, M. Datcheva, and T. Schanz, "Rigorous solution for 1-D consolidation of a clay layer under haversine cyclic loading with rest period," SpringerPlus, vol. 5, no. 1, article no. 1987, 2016.

[6] A. Qin, D. Sun, and J. Zhang, "Semi-analytical solution to onedimensional consolidation for viscoelastic unsaturated soils," Computers \& Geosciences, vol. 62, pp. 110-117, 2014.

[7] L. Wang, D. Sun, P. Li, and Y. Xie, "Semi-analytical solution for one-dimensional consolidation of fractional derivative viscoelastic saturated soils," Computers \& Geosciences, vol. 83, pp. 30-39, 2017.
[8] R. E. Gibson, "The Progress of Consolidation in a Clay Layer Increasing in Thickness with Time," Géotechnique, vol. 8, no. 4, pp. 171-182, 1958.

[9] S. S. Razouki and T. Schanz, "One-dimensional consolidation under haversine repeated loading with rest period," Acta Geotechnica, vol. 6, no. 1, pp. 13-20, 2011.

[10] S. S. Razouki, P. Bonnier, M. Datcheva, and T. Schanz, "Analytical solution for $1 \mathrm{D}$ consolidation under haversine cyclic loading," International Journal for Numerical and Analytical Methods in Geomechanics, vol. 37, no. 14, pp. 2367-2372, 2013.

[11] M. S. Mahmoud and H. Deresiewicz, "Settlement of inhomogeneous consolidating soils-I: The single-drained layer under confined compression," International Journal for Numerical and Analytical Methods in Geomechanics, vol. 4, no. 1, pp. 57-72, 1980.

[12] G. Zhu and J.-H. Yin, "Analysis and mathematical solutions for consolidation of a soil layer with depth-dependent parameters under confined compression," International Journal of Geomechanics, vol. 12, no. 4, pp. 451-461, 2012.

[13] X. W. Tang, B. Niu, G. C. Cheng, and H. Shen, "Closed-form solution for consolidation of three-layer soil with a vertical drain system," Geotextiles and Geomembranes, vol. 36, pp. 8191, 2013.

[14] G.-X. Mei and Q.-M. Chen, "Solution of Terzaghi one-dimensional consolidation equation with general boundary conditions," Journal of Central South University, vol. 20, no. 8, pp. 2239-2244, 2013.

[15] B. C. Hawlader, B. Muhunthan, and G. Imai, "State-dependent constitutive model and numerical solution of self-weight consolidation," Géotechnique, vol. 58, no. 2, pp. 133-141, 2008.

[16] M. A. Rahalt and A. R. Vuez, "Analysis of settlement and pore pressure induced by cyclic loading of silo," Journal of Geotechnical and Geoenvironmental Engineering, vol. 124, no. 12, pp. 1208-1210, 1998.

[17] E. H. Davis and G. P. Raymond, "A non-linear theory of consolidation,” Géotechnique, vol. 15, no. 2, pp. 161-173, 1965.

[18] E. Conte and A. Troncone, "Soil layer response to pore pressure variations at the boundary," Géotechnique, vol. 58, no. 1, pp. 3744, 2008.

[19] V. Pane and R. L. Schiffman, "A note on sedimentation and consolidation," Géotechnique, vol. 35, no. 1, pp. 69-72, 1985.

[20] R. E. Gibson, "A heat conduction problem involving a specified moving boundary," Quarterly of Applied Mathematics, vol. 16, no. 4, pp. 426-430, 1959.

[21] R. L. Schiffman, "Consolidation of soil under time-dependent loading and varying permeability," in Proceedings of the ThirtySeventh Annual Meeting of the Highway Research Board, vol. 37, pp. 584-617, 1958.

[22] K. S. He, Z. J. Shen, and X. X. Peng, "The comparison of large strain method using total and updated Lagrangian finite element formulation and small strain method," Chinese Journal of Geotechnical Engineering, vol. 22, no. 1, pp. 30-34, 2000.

[23] G. Mesri and R. E. Olson, "Mechanisms controlling the permeability of clays," Clays and Clay Minerals, vol. 19, no. 3, pp. 151158, 1971.

[24] Y.-C. Zhuang, K.-H. Xie, and X.-B. Li, "Nonlinear analysis of consolidation with variable compressibility and permeability," Journal of Zhejiang University (Engineering Science), vol. 6, no. 3, pp. 181-187, 2005.

[25] E. Conte and A. Troncone, "Nonlinear consolidation of thin layers subjected to time-dependent loading," Canadian Geotechnical Journal, vol. 44, no. 6, pp. 717-725, 2007. 


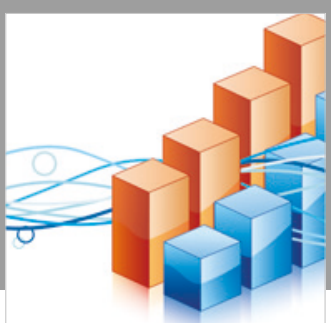

Advances in

Operations Research

\section{-n-m}
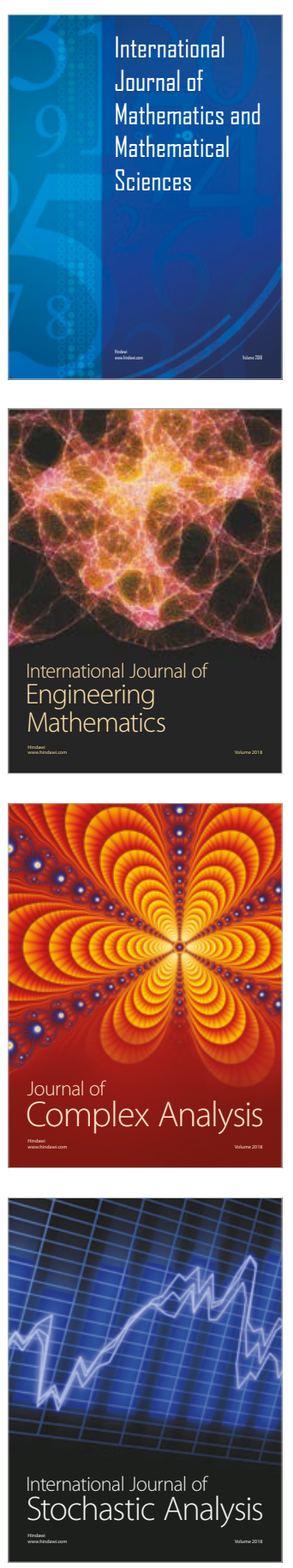
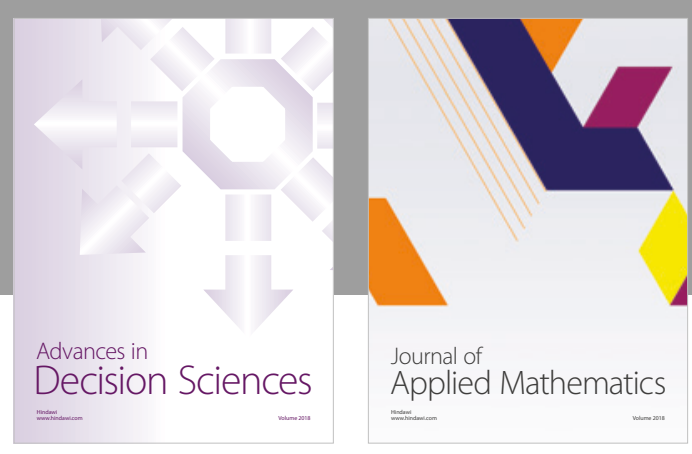

Journal of

Applied Mathematics
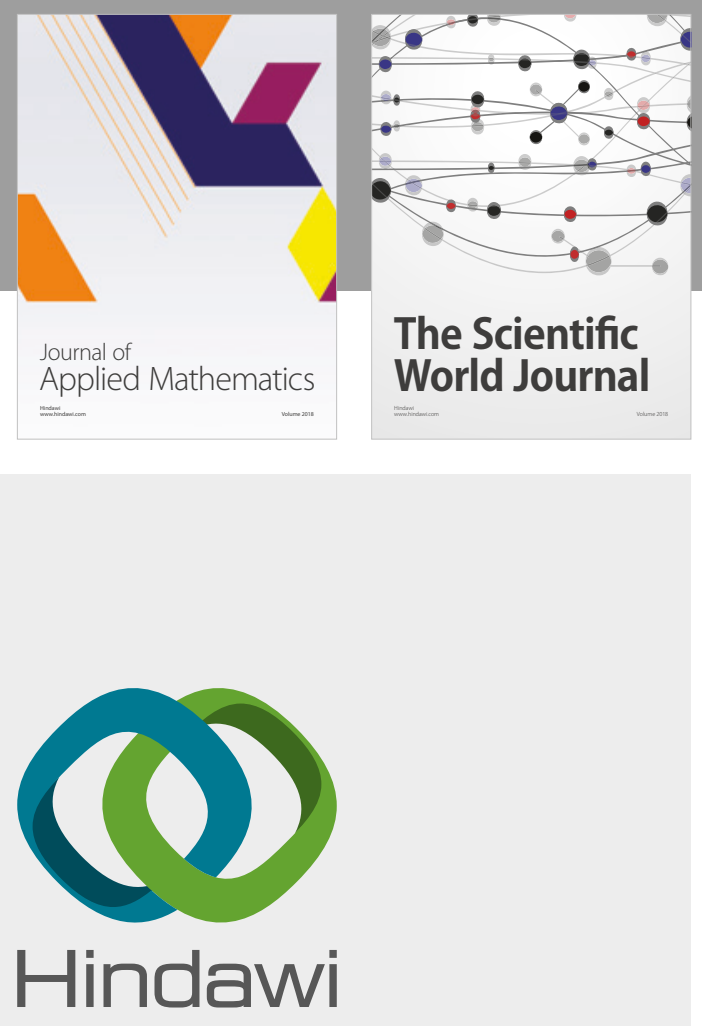

Submit your manuscripts at

www.hindawi.com

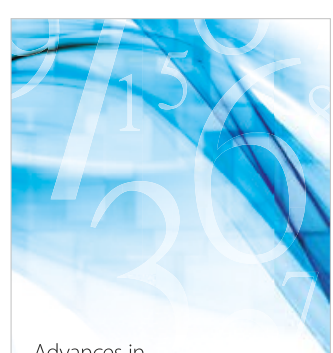

Advances in
Numerical Analysis
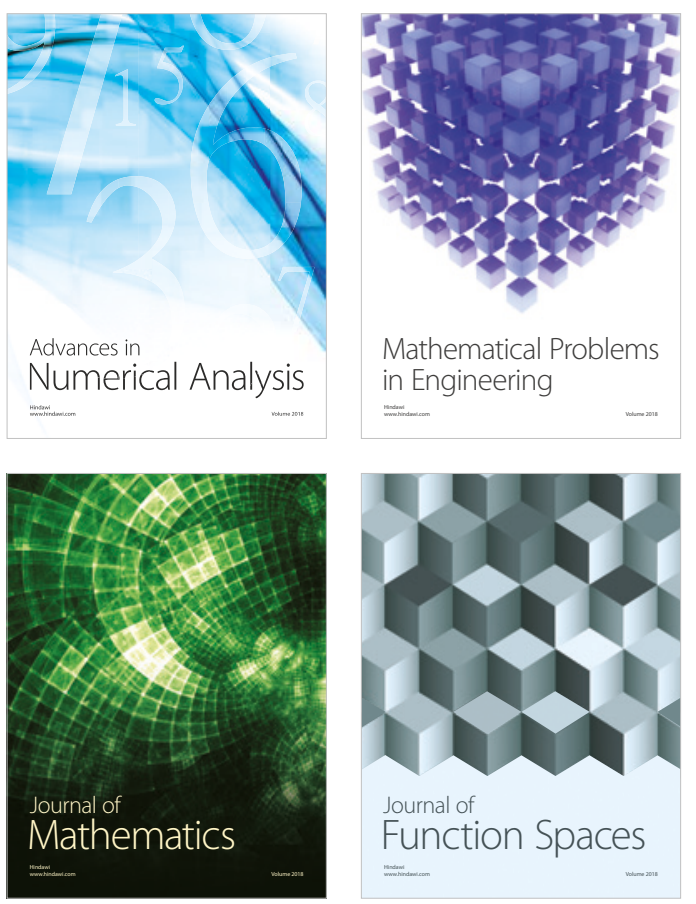

Mathematical Problems in Engineering

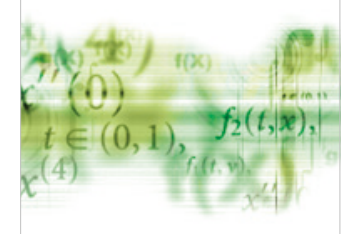

International Journal of

Differential Equations

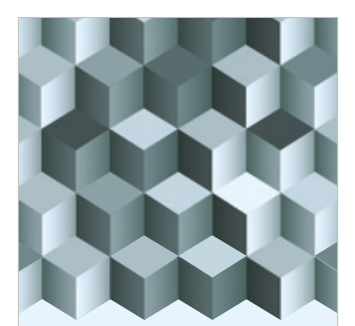

Journal of

Function Spaces

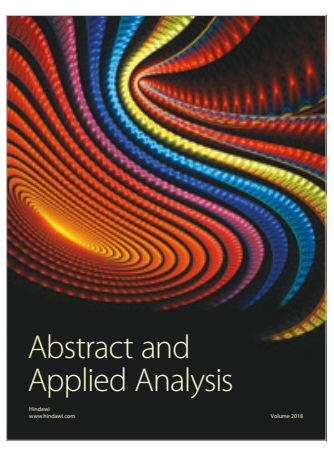

The Scientific

World Journal

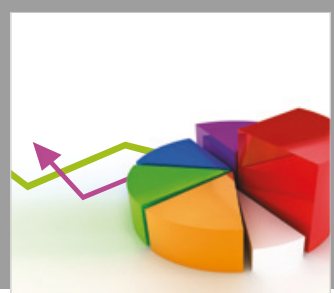

Journal of

Probability and Statistics
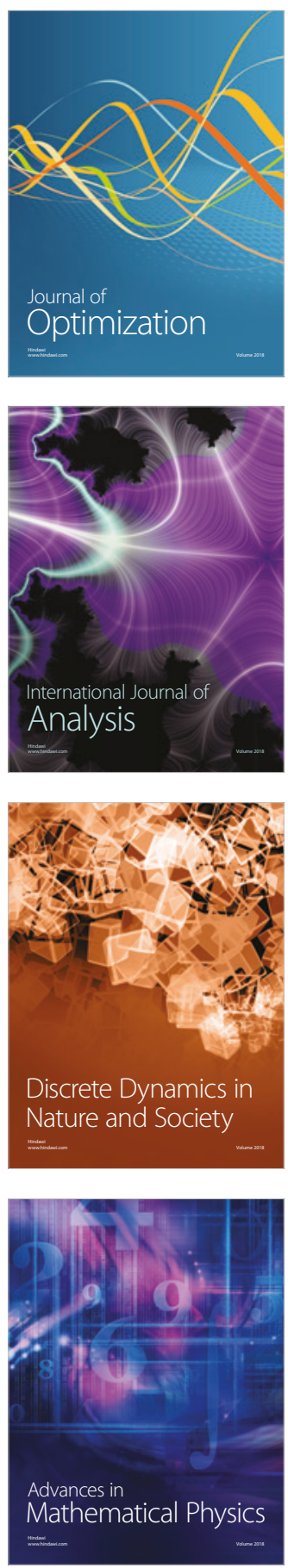